\title{
Predicting First-Year Mortality in Incident Dialysis Patients with End-Stage Renal Disease - The UREA5 Study
}

\author{
Horng-Ruey Chua ${ }^{a, c}$ Titus Lau ${ }^{a, c}$ Nan Luo ${ }^{d}$ Valerie Ma ${ }^{a}$ Boon-Wee Teo ${ }^{a, c}$ \\ Sabrina Haroon ${ }^{a, c}$ Kwan-Loong Choy ${ }^{a, c}$ Yoke-Ching Lim ${ }^{a}$ Wei-Qiang Chng ${ }^{c}$ \\ Li-Zhen Ong $^{\text {b, c }}$ Tsz-Yeung Wong ${ }^{a}$ Evan J. Lee Le, $^{\mathrm{a}}$ \\ ${ }^{a}$ Division of Nephrology, University Medicine Cluster, and ${ }^{\mathrm{b}}$ Department of Laboratory Medicine, National University \\ Hospital, ' Department of Medicine, Yong Loo Lin School of Medicine, and d Saw Swee Hock School of Public Health, \\ National University of Singapore, Singapore
}

\section{Key Words}

Alkaline phosphatase - Cardiovascular disease .

Cerebrovascular disease - End-stage renal disease - Early mortality · Hyperuricemia $\cdot$ Hypoalbuminemia $\cdot$ Incident dialysis - Left ventricular dysfunction · Peripheral vascular disease

\begin{abstract}
We aimed to develop a risk prediction model for first-year mortality (FYM) in incident dialysis patients with end-stage renal disease. We retrospectively examined patient comorbidities and biochemistry, prior to dialysis initiation, using a single-center, prospectively maintained database from 2005-2010, and analyzed these variables in relation to FYM. A total of 983 patients were studied. $22 \%$ had left ventricular ejection fraction (LVEF) $<45 \%$. FYM was $17 \%$, and independent predictors included URate $<500$ or $>600 \mu \mathrm{mol} / \mathrm{l}$, LVEF $<45 \%$ (higher odds ratio if $<30 \%$ ), Age $>70$ years, Arteriopathies (cerebrovascular and/or peripheral-vascular diseases), serum Albumin $<30 \mathrm{~g} / \mathrm{l}$, and Alkaline phosphatase $>80 \mathrm{U} / \mathrm{l}$ ( $p<0.05, C$-statistic 0.74$)$, and these constitute the acronym UREA5. Using linear modeling, risk weightage/integer of 3
\end{abstract}

\section{KARGER}

E-Mail karger@karger.com

www.karger.com/bpu was assigned to LVEF $<30 \%, 2$ to age $>70$ years, and 1 to each remaining variable. Cumulative UREA5 scores of $\leq 1,2,3,4$, and $\geq 5$ were associated with FYM of $6,8,22,31$, and $46 \%$, respectively ( $p<0.0001)$. Increasing UREA5 scores were strongly associated with stepwise worsening of FYM after dialysis initiation.

(c) 2014 S. Karger AG, Basel

\section{Introduction}

The incidence of end-stage renal disease (ESRD) has increased locally by $30-40 \%$ in the last decade, with an annual age-standardized dialysis incidence and prevalence of 168 and 948 patients per million population, respectively [1]. Dialysis has a massive impact on financial resources and utilization. Patients with ESRD also experience reduced life expectancy, increased cardiovascular morbidities and recurrent hospitalization that worsen the healthcare burden [2]. Additionally, these patients have a higher mortality rate of 3-8 times compared to the general population despite the aggressive medical intervention [3]. (c) 2014 S. Karger AG, Basel

0253-5068/14/0372-0085\$39.50/0
Dr. Horng-Ruey Chua

University Medicine Cluster, National University Health System

Level 10 NUHS Tower Block, 1E Kent Ridge Road

Singapore 119228 (Singapore)

E-Mail horng_ruey_chua @ nuhs.edu.sg 
In that regard, first-year mortality (FYM) rates in incident dialysis patients have been relatively unchanged, despite steady decline in death rates in the prevalent population [4]. This is in tandem with various complications encountered at dialysis initiation, including vascular access, infectious, and cardiovascular-related issues [5]. These translate to unacceptably high hospitalization and mortality rates in the initial year [6], and affect the patients' quality of life adversely. Identification of patients at high risk of early mortality may allow targeted intervention strategies to improve first-year outcomes, but such studies are limited.

Therefore, we aimed to describe the profile of incident dialysis patients with FYM, and examine factors associated with early death. We hypothesized that determination of these key predictors of early mortality will enable the formulation of an effective risk prediction scoring system for clinical use.

\section{Methods}

\section{Design and Population}

We conducted a single-center observational study of patients with ESRD who were newly initiated on hemodialysis (HD) or peritoneal dialysis (PD) from January 2005 to December 2010. The patient list was retrieved from the hospital's prospectively maintained ESRD database. The Domain Specific Review Board (National Healthcare Group, Singapore) approved the study (ref. 2011/02187), and waived the need for informed consent. All adult ESRD patients aged $>18$ years were studied. Patients who underwent kidney transplantation preemptively or within one year of dialysis initiation were excluded.

\section{Definitions and Data Collection}

Baseline patient demographics and comorbidities were indexed at time of dialysis initiation; the latter was defined as date of ESRD. 'No access' referred to dialysis initiated via a vascular catheter, and not via a functional permanent access. 'Planned renal replacement therapy (RRT)' referred to patients with chronic kidney disease (CKD) who received $>6$ months of nephrology followup and were appropriately counseled prior to dialysis initiation, with or without a functional permanent access at initiation. Decision for HD or PD selection in patients with planned RRT is jointly decided by the nephrologist in attendance and the patient, and highly influenced by social circumstances. Chief reasons for choosing HD included lack of confidence or caregiver for home-based therapy, and PD reasons included time flexibility and difficulty with travelling [unpubl. internal data]. These patients routinely underwent 2-D echocardiogram, within one year prior to projected dialysis initiation. Alternatively, patients had the 2-D echocardiogram performed if clinically indicated, or within 3 months of dialysis initiation. Left ventricular (LV) ejection fraction (LVEF) at rest was recorded.

Comorbidities prospectively documented in the database include ischemic heart disease (IHD), defined as coronary angio- gram findings of $>50 \%$ luminal vessel stenosis, positive cardiac stress tests, or diagnosed acute coronary syndrome. Cerebrovascular disease (CVA) referred to history of ischemic stroke, transient ischemic attack, or intracranial hemorrhage. Peripheral vascular disease (PVD) was classified either in general, or as significant PVD that included foot gangrene or amputation.

Biochemistry was retrospectively collected from electronic records, and included hemoglobin, serum albumin, urea, creatinine, corrected calcium, phosphate, alkaline phosphatase (ALP), urate, and intact parathyroid hormone (iPTH). We used the 4-variable MDRD equation to estimate glomerular filtration rate (eGFR) [7]. All results were retrieved within 6 months prior to ESRD date, except for iPTH, for which the validity was extended to within 3 months after dialysis initiation.

\section{First-Year Outcomes}

Survival duration (days) was calculated from date of ESRD until death, or censored on 12th March 2012 for survivors. Ninetyday and first-year mortality were defined as survival days $\leq 90$ and $\leq 365$ days, respectively. Primary cause of death including major adverse cardiac events (MACE) was retrieved from mortality records, and MACE was defined as a composite of acute myocardial infarction, congestive cardiac failure, or sudden cardiac death.

\section{Data Analysis}

Demographics, comorbidities and biochemistry were compared between patients with early death versus survivors, and analyzed using parametric or nonparametric tests where appropriate. All clinically plausible variables were examined for their association with 90-day and first-year mortality using separate univariate logistic regression models. Statistically significant clinical variables were included in multivariate logistic regression models to look for independent predictors of 90-day and first-year mortality. As the relationship with mortality may not be linear, all continuous variables were coded into categorical variables according to clinical definitions or data distributions in the modeling analysis. The number of categories was reduced for each variable by combing insignificant categories in the univariate analysis. For example, age was initially coded into 4 categories ( $\leq 50$ years, $51-60$ years, $61-70$ years, and $>70$ years). In the univariate analysis, the 3 younger age groups had similar effects on mortality versus the oldest age group. Hence, age was recoded as $\leq 70$ versus $>70$ years. Likewise, similar statistical cutoffs were established for ALP and urate for multivariate analysis. Albumin was recoded as $<30$ versus $\geq 30 \mathrm{~g} / \mathrm{l}$, and LVEF recoded with cutoffs at 30 and $45 \%$, in view of adverse prognosis in ESRD at lower ranges of both variables $[8,9]$.

The final prediction model for FYM (formula 1) was developed using stepwise selection method, with the $\mathrm{p}$ value for inclusion being 0.05 . The model fit was assessed using C-statistic, and Hosmer-Lemeshow test. Probability of first-year death predicted by the final logistic model was regressed on the predictors to estimate a linear model (formula 2). The linear model was then simplified by linear transformation, and its coefficients converted into integers of 1,2 , or 3 (formula 3 ). The precision of the formulas in predicting mortality risk was assessed using C-statistic. Analysis was performed using SAS v9.2 (2009, Cary, N.C., USA). 
Table 1. Baseline demographics, comorbidities, ESRD care details, and laboratory values

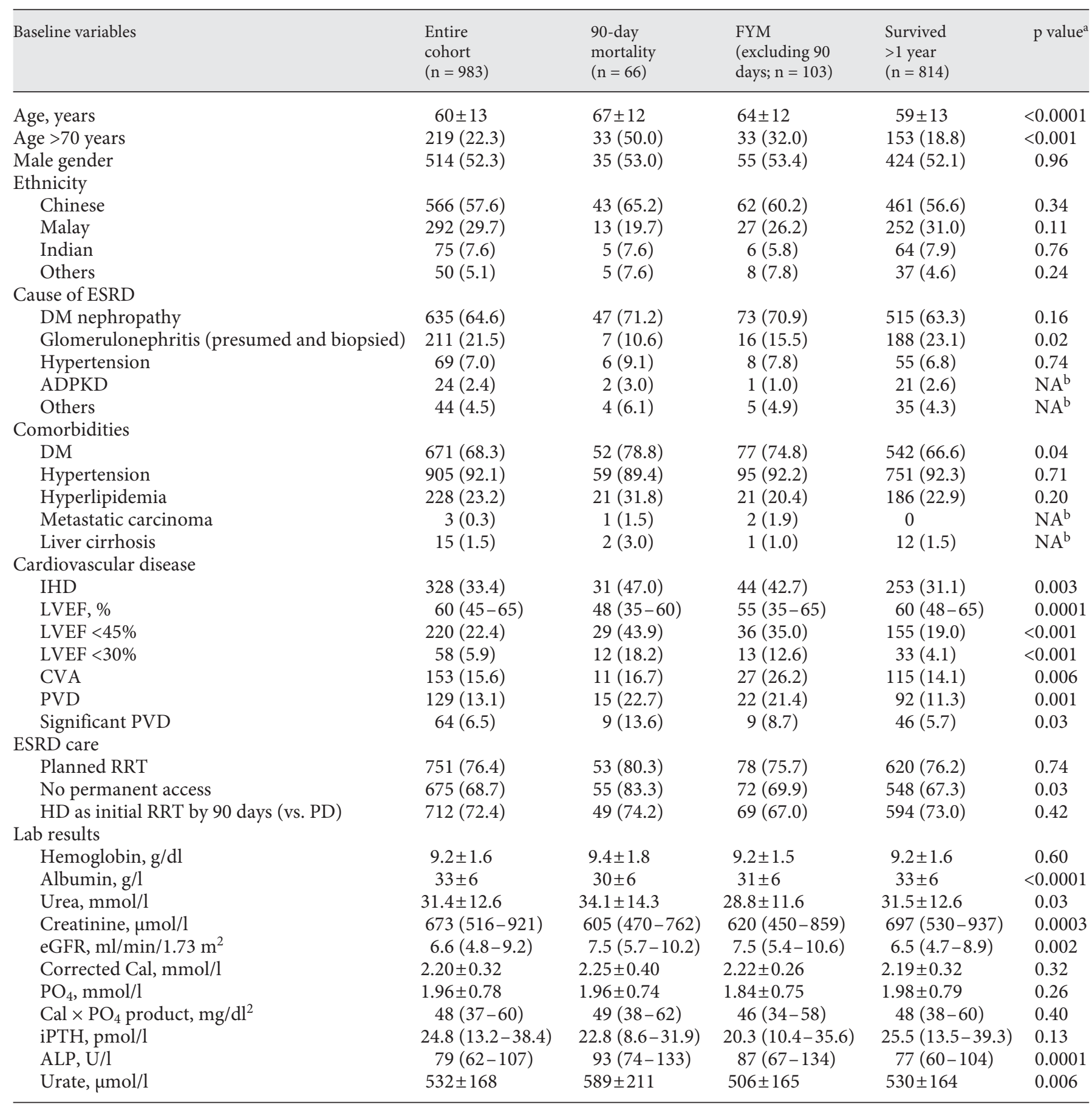

Data are presented as $\mathrm{n}(\%)$, mean \pm SD or median $(\mathrm{IQR})$. ADPKD = Autosomal dominant polycystic kidney disease; Cal = calcium; $\mathrm{PO}_{4}=$ phosphate.

a Statistical comparison between subgroups with 90-day mortality, FYM, and survivors beyond the first year.

${ }^{\mathrm{b}}$ Invalid $\chi^{2}$ results as frequency $<5$. 
Table 2. Primary causes of FYM

\begin{tabular}{lccc}
\hline Cause of death & $\begin{array}{l}\text { 90-day } \\
\text { mortality } \\
(\mathrm{n}=66)\end{array}$ & $\begin{array}{l}\text { FYM } \\
\text { (excluding } \\
90 \text { days; } \\
\mathrm{n}=103)\end{array}$ & $\begin{array}{l}\text { Total } \\
\text { deaths } \\
(\mathrm{n}=169)\end{array}$ \\
\hline MACE & $12(18.2)$ & $20(19.4)$ & $32(18.9)$ \\
Pneumonia & $5(7.6)$ & $16(15.5)$ & $21(12.4)$ \\
IntraAbd sepsis/peritonitis & $2(3.0)$ & $4(3.9)$ & $6(3.6)$ \\
Lower limb infection $_{\text {Access-related sepsis }}{ }^{\mathrm{a}}$ & $4(6.1)$ & $1(1.0)$ & $5(3.0)$ \\
Sepsis NOS/others & $1(1.5)$ & 0 & $1(0.6)$ \\
ESRD NOS & $3(4.6)$ & $7(6.8)$ & $10(5.9)$ \\
CVA & $7(10.6)$ & $16(15.5)$ & $23(13.6)$ \\
Others/unknown & $2(3.0)$ & $2(1.9)$ & $4(2.4)$ \\
\hline
\end{tabular}

Data are presented as $\mathrm{n}(\%)$. IntraAbd = Intra-abdominal; NOS $=$ not otherwise specified. ${ }^{a}$ Refers to HD access-related infections, including tunneled catheters and arteriovenous grafts.

Table 3. Multivariate logistic regression results

\begin{tabular}{|c|c|c|c|}
\hline $\begin{array}{l}\text { Significant independent } \\
\text { variables }\end{array}$ & $\begin{array}{l}\text { Odds } \\
\text { ratio }\end{array}$ & $\begin{array}{l}95 \% \\
\text { Wald CI }\end{array}$ & $\mathrm{p}$ value \\
\hline \multicolumn{4}{|l|}{ Predictors of 90-day mortality } \\
\hline Age $>70$ years & 4.77 & $2.73-8.34$ & $<0.0001$ \\
\hline LVEF $30-44 \%$ & 2.15 & $1.13-4.08$ & 0.02 \\
\hline LVEF $<30 \%$ & 4.41 & $1.97-9.89$ & 0.0003 \\
\hline No permanent access ${ }^{\mathrm{a}}$ & 2.44 & $1.22-4.91$ & 0.01 \\
\hline Significant PVD & 3.84 & $1.67-8.85$ & 0.002 \\
\hline Serum albumin $<30 \mathrm{~g} / \mathrm{l}$ & 2.30 & $1.33-3.96$ & 0.003 \\
\hline Serum urate $\geq 600 \mu \mathrm{mol} / 1$ & 2.25 & $1.31-3.88$ & 0.004 \\
\hline \multicolumn{4}{|l|}{ C-statistic: 0.80} \\
\hline \multicolumn{4}{|l|}{ Hosmer-Lemeshow test: $\mathrm{p}=0.73$} \\
\hline \multicolumn{4}{|l|}{ Predictors of FYM } \\
\hline Age $>70$ years & 3.37 & $2.25-5.04$ & $<0.0001$ \\
\hline LVEF $30-44 \%$ & 1.81 & $1.15-2.86$ & 0.01 \\
\hline LVEF <30\% & 4.92 & $2.67-9.10$ & $<0.0001$ \\
\hline CVA & 1.74 & $1.09-2.77$ & 0.02 \\
\hline PVD & 2.14 & $1.33-3.45$ & 0.002 \\
\hline Serum albumin $<30 \mathrm{~g} / \mathrm{l}$ & 1.71 & $1.16-2.52$ & 0.007 \\
\hline Serum ALP $>80 \mathrm{U} / 1$ & 1.67 & $1.14-2.46$ & 0.009 \\
\hline Serum urate $500-600 \mu \mathrm{mol} / \mathrm{l}$ & 0.57 & $0.36-0.92$ & 0.02 \\
\hline \multicolumn{4}{|l|}{ C-statistic: 0.74} \\
\hline Hosmer-Lemeshow test: $\mathrm{p}=0.21$ & & & \\
\hline
\end{tabular}

Factors considered in multivariate models: age at initiation; male gender; ethnicity; DM; hypertension; hyperlipidemia; IHD; CVA; PVD/significant PVD; liver cirrhosis; metastatic carcinoma; DM nephropathy; chronic glomerulonephritis; hypertensive ESRD; ADPKD; LVEF; planned RRT; no permanent access ${ }^{\text {a }}$ labs: hemoglobin, albumin, urea, eGFR, iPTH, Cal, $\mathrm{PO}_{4}, \mathrm{Cal} \times \mathrm{PO}_{4}$, ALP, urate. $\mathrm{CI}=$ Confidence interval. ${ }^{\text {a }}$ Failure to initiate dialysis via a matured arteriovenous access or Tenckhoff catheter.

\section{Results}

A total of 983 multiethnic Asian patients were included in the final analysis. The mean age was $60( \pm 13)$ years, $52.3 \%$ were males, and $64.6 \%$ had diabetes mellitus (DM) nephropathy as cause of ESRD. 33.4\% had known IHD at baseline, with $22.4 \%$ having baseline LVEF $<45 \%$. Most patients (76.4\%) had planned RRT, but $68.7 \%$ commenced HD with no permanent access. $72.4 \%$ of patients underwent HD as initial RRT modality by 90 days (vs. PD). These and the baseline hematology and biochemistry profiles are shown in table 1.

Of 983 patients, $66(6.7 \%)$ died within 90 days, and a further 103 (10.5\%) died after 90 days to within one year from dialysis initiation. The incidence of FYM was 169 of 983 patients (17.2\%). By univariate comparison, FYM patients were significantly older $(\mathrm{p}<0.001)$, and more had baseline DM ( $p=0.04)$, as well as IHD, CVA, and PVD $(\mathrm{p}<0.01)$. Patients who died early also had significantly lower baseline LVEF, no permanent access, lower serum albumin, and higher eGFR, serum urea, ALP, and urate (table 1). More patients with lower urate $(<500 \mu \mathrm{mol} / \mathrm{l})$ also had albumin $<30 \mathrm{~g} / \mathrm{l}$, compared to those with higher urate (32 vs. $26 \%$, respectively, $\mathrm{p}=0.03$ ).

The majority of known causes of death in the first year were attributed to MACE and pneumonia, which together accounted for $>30 \%$ of deaths. Other more notable causes of death included intra-abdominal sepsis (including peritonitis) and lower limb infections (table 2).

Table 3 shows the results of multivariate analysis, and list of variables entered into the logistic regression model. Independent predictors of both 90-day and first-year mortality include age $>70$ years, $\mathrm{LVEF}<45 \%$ (with higher odds ratio for $\mathrm{LVEF}<30 \%$ ), and serum albumin $<30 \mathrm{~g} / \mathrm{l}$. In addition, no access at initiation, significant PVD, and serum urate $\geq 600 \mu \mathrm{mol} / \mathrm{l}$ predicted 90 -day mortality, whereas CVA, PVD (in general), serum ALP $>80 \mathrm{U} / 1$, and either extremes of serum urate $<500$ or $>600 \mu \mathrm{mol} / \mathrm{l}$ were independently associated with FYM.

Table 4 shows the predictive equations derived by logistic and linear remodeling, using the independent predictors of (and their respective odds ratios) FYM. The final equation (3) represented the simplified linear model with coefficients of all factors rounded off to the nearest integers. The highest risk weightage of 3 was assigned to LVEF $<30 \%$, followed by weightage of 2 assigned to age $>70$ years, and weightage of 1 for the remaining risk factors. The simplified model 3 performed with comparable specificity to the preceding formulas 1 and 2, with areas under the curve of $0.74,0.74$, and 0.75 , respectively, 
Table 4. Formulation of the UREA5 score

a Predictive equations by logistic and linear remodeling

$\begin{array}{ll}\text { Formula 1: } & \text { logistic model using significant variables a/w FYM } \\ \text { Score: } & (\text { age }>70 \text { years })+(\text { LVEF } 30-44 \%)+(\text { LVEF }<30 \%) \\ & +(\text { CVA })+(\mathrm{PVD})+(\mathrm{Alb}<30)+(\mathrm{ALP}>80)+ \\ & (\text { urate }<500 \text { or }>600) \\ & \text { (similar weightage of ' } 1 \text { ' given if variable present, or } \\ & \text { '0' if absent) }\end{array}$

Formula 2: linear model using the above variables

Score: $\quad-0.02827+($ age $>70$ years $) \times 0.18688+(\mathrm{LVEF}$ $30-44 \%) \times 0.08186+(\mathrm{LVEF}<30 \%) \times 0.28181+$ $(\mathrm{CVA}) \times 0.08669+(\mathrm{PVD}) \times 0.12056+(\mathrm{Alb}<30) \times$ $0.08102+($ ALP $>80) \times 0.06806+($ urate $<500$ or $>600) \times 0.06797$

(weightages shown are regression coefficients from linear model; probabilities predicted from the logistic model)

Formula 3: simplified linear model using above variables (UREA5 score)

Score: $\quad($ age $>70$ years $) \times 2+($ LVEF $30-44 \%) \times 1+($ LVEF $<30 \%) \times 3+(\mathrm{CVA}) \times 1+(\mathrm{PVD}) \times 1+(\mathrm{Alb}<30) \times$ $1+($ ALP $>80) \times 1+($ urate $<500$ or $>600) \times 1$ (weightages in formula 2 are rounded off to 1,2 , and 3)

Alb = Serum albumin

b FYM predictions

\begin{tabular}{clll}
\hline UREA5 score $^{\text {a }}$ & $\begin{array}{l}\text { Numbers per } \\
\text { category }^{\mathrm{a}}\end{array}$ & $\begin{array}{l}\text { FYM, } \\
\text { n (row \%) }\end{array}$ & $\begin{array}{l}\text { Survived >1 year, } \\
\mathrm{n}(\text { row \%) }\end{array}$ \\
\hline$\leq 1$ & 219 & $12(5.5)$ & $207(94.5)$ \\
2 & 206 & $17(8.3)$ & $189(91.8)$ \\
3 & 198 & $44(22.2)$ & $154(77.8)$ \\
4 & 121 & $37(30.6)$ & $84(69.4)$ \\
$\geq 5$ & 106 & $49(46.2)$ & $57(53.8)$ \\
\hline Total & $850^{\text {a }}$ & $159(18.7)$ & $691(81.3)$ \\
\hline
\end{tabular}

${ }^{a}$ Excluding 133 patients with incomplete variables to calculate the UREA5 score.

by receiver operating characteristic analysis. The acronym UREA5 describes this FYM risk score obtained from the following baseline parameters: URate, EF, Age, Arteriopathy-PVD, Arteriopathy-CVA, Albumin, and ALP. Increasing UREA5 score was associated with stepwise increase in mortality numbers during the first year of dialysis initiation ( $\mathrm{p}<0.0001$, log-rank test), with a score of $\geq 5$ being associated with $46 \%$ FYM (table 4; fig. 1).

\section{Discussion}

\section{Key Findings and Relationship with Past Studies}

The FYM in our incident dialysis ESRD cohort was $17 \%$, comparable to large cohort studies from Canada and US DOPPS $[6,10]$. It is higher than that reported from Korea, which was $<10 \%$ FYM in a younger Asian ESRD cohort (mean 57 vs. 60 years in our study) [11]. Key mortality predictors included advanced age, LV dysfunction (especially LVEF <30\%), CVA, PVD, high serum ALP, hypoalbuminemia and either extremes of serum urate. These factors constitute the prognostic UREA5 score, and increasing score correlated with stepwise worsening of mortality rates in our cohort. The chief cause of death was MACE, and all mortality predictors are also interlinked to cardiovascular health. Impaired LVEF was the strongest mortality predictor. LV dysfunction at dialysis initiation is common, and predisposing factors include coronary ischemia, hypertension, volume overload, anemia, uremia, and renin-angiotensin-aldosterone activation $[12,13]$. Impaired LVEF may however improve with regular dialysis [14], and by itself cannot be taken to strictly define cardiovascular health.

Therefore, the prognostic significance of LV dysfunction needs to be interpreted along with its severity and other markers of vascular health. LVEF $<30 \%$ has a much higher odds ratio for death, and this supports recent data $[9,13]$. We have also shown that the presence of clinically manifest cardiovascular diseases such as CVA and PVD adds prognostic value. Several contributing factors of CVA and PVD include advanced age, atrial fibrillation, DM and hypertension, all commonly seen in ESRD [15-17]. LV dysfunction, CVA, and PVD represent severe underlying cardiovascular disease burden. It is thus entirely plausible that these factors outperform the traditional cardiac risk factors such as DM in predicting early death.

The addition of relevant biochemistry may aid mortality prediction [18]. Hypoalbuminemia has been consistently shown by our and previous studies, to be strongly associated with death in ESRD $[6,18,19]$. While hypoalbuminemia is frequently ascribed to anorexia and malnutrition, studies suggest more complex etiologies such as chronic inflammation and acidosis with CKD [20]. More recently, the interlink between raised inflammatory markers, hypoalbuminemia, and cardiovascular events in CKD has been emphasized [21]. Albumin is also a negative acute-phase reactant, and low levels could signify severity of acute illnesses at dialysis initiation that imply poorer prognosis. 
Fig. 1. Kaplan-Meier survival analysis by different tiers of UREA5 risk score, and proportion of patients alive at 0,100, 200, and 300 days from dialysis initiation. $\mathrm{p}<$ $0.0001, \log$-rank test.

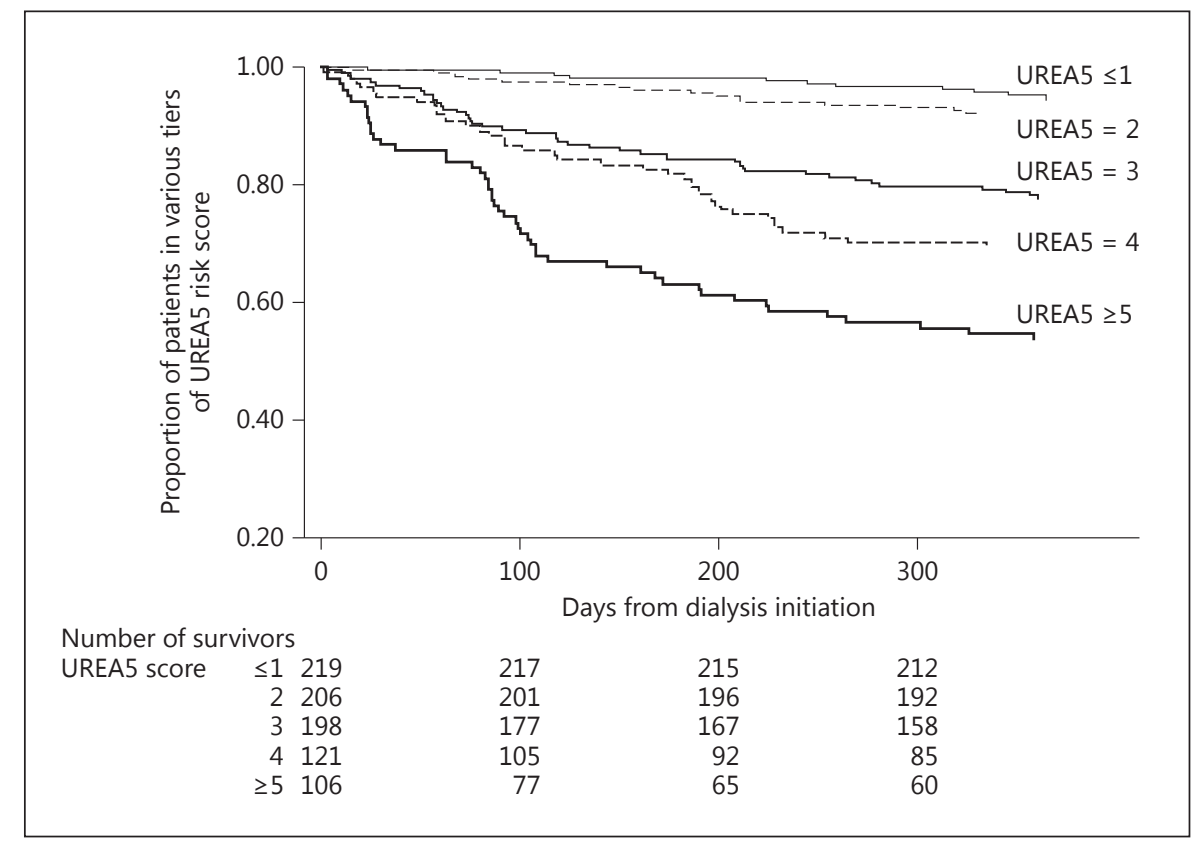

Recent data have described the robust association between raised ALP and poor survival in HD patients, and such association persists across different PTH strata [22]. We found that ALP $>80 \mathrm{U} / 1$ predicted early mortality, which remained significant after adjustment for iPTH. Raised ALP results in increased hydrolysis of pyrophosphate, which otherwise is a potent inhibitor of vascular calcification [23], hence again establishing the former's link with vascular health. Likewise, hyperuricemia is increasingly recognized as a marker of cardiovascular morbidity [24]. It may either be related to urate's pro-oxidative effects on vascular cells and endothelial dysfunction [25], or indirectly related to the synergistic actions of coexisting vascular risk factors and metabolic syndrome [26]. On the other hand, the finding that hypouricemia also predicts early mortality reinforces previous findings [27]. Possible explanation may be that hypouricemia is seen in protein malnutrition, and our finding that more patients with low urate had concomitant hypoalbuminemia supports this.

\section{Strengths and Limitations}

We have included 9 commonly performed hematology and biochemical variables, and tested the robustness of the mortality predictors after adjusting for multiple covariates. The resultant UREA5 score is simple to calculate and easily applied, being based on routine clinical, laboratory, and echocardiographic parameters. The bulk of clinical data was maintained prospectively as part of quality assurance, and $90 \%$ of these patients have LVEF assessed at baseline. The laboratory variables were collected retrospectively, but these data were available in electronic health records and thus minimized ascertainment bias. The mortality predictors are closely related to cardiovascular health, and results were strong and clinically plausible.

Though our study sample was relatively small compared to other risk derivation studies, we were able to include a much wider range of risk factors. Differences in our patients' profile compared to other developed countries may limit generalizability of our findings. For example, our reported diabetic prevalence was 68 versus 40 and 50\% from North American and Korean studies, respectively $[6,10,11]$. Compared to baseline biochemistry from the UK Renal Registry, our patients were more anemic (hemoglobin 9 vs. $11 \mathrm{~g} / \mathrm{dl}$ ), with lower serum albumin (33 vs. $35 \mathrm{~g} / \mathrm{l}$ ) [18], and these may suggest higher comorbid burden at dialysis initiation in our cohort. Our patients were however relatively younger (60 vs. 63-64 years in North American and UK studies), with slightly less IHD (33\% locally vs. $40-50 \%$ in North America) $[6,10$, 18]. We did not collect functional indices, which also could not be assessed retrospectively, and these may be important given the prognostic significance of CVA and PVD. Our study is single center in nature and requires confirmation in other healthcare systems.
Chua/Lau/Luo/Ma/Teo/Haroon/Choy/ Lim/Chng/Ong/Wong/Lee 
Clinical Relevance and Conclusions

Patients with baseline high UREA5 score $\geq 5$ may benefit from recruitment into a dialysis-transition program for closer dry weight titration and erythropoietin adjustments, with the aim to reduce early mortality. Alternatively, this risk score may serve as a useful prognostic tool for more informed patient counseling and/or advance care planning, as elderly patients with high comorbid burden may not fare well functionally even with dialysis [28]. Our study highlights the importance of cardiovascular health in influencing patient-centered outcomes, and correlation studies with more objective markers such as arterial stiffness and cardiac biomarkers are welcome. The identification of mortality predictors with potential for reversal such as ALP and urate may provide the basis for trials involving these as therapeutic targets, such as vitamin $\mathrm{D}$ and urate-lowering therapies. The prognostic value of LV function may prompt physicians to examine this parameter routinely. Our results however need to be externally validated in a multicenter patient cohort before routine clinical application. Nevertheless, implementation of a simple and effective mortality risk stratification tool may provide more evidence-based allocation of healthcare resources in the management of an otherwise extremely debilitating disease with adverse prognosis.

\section{Acknowledgements}

The authors would like to thank the dialysis coordinators from the National University Hospital Singapore for the maintenance of the ESRD database, and Mr. Ming-Wei Xie and Mr. Han-Jie Lee from the NUS High School of Mathematics and Science for their invaluable assistance in biochemistry data collection.

\section{Disclosure Statement}

The authors have no conflicts of interest to declare.

\section{References}

1 Lee EJ, Choong HL, Vathsala A, Chow KY: Singapore Renal Registry Annual Registry Report 1999-2012 (preliminary). Singapore, National Registry of Diseases Office (NDRO) HPB, 2013, pp 1-18.

2 Sehgal AR, Dor A, Tsai AC: Morbidity and cost implications of inadequate hemodialysis. Am J Kidney Dis 2001;37:1223-1231.

3 US Renal Data System, USRDS 2010 Annual Data Report: Atlas of Chronic Kidney Disease and End-Stage Renal Disease in the United States. Bethesda, National Institutes of Health, National Institute of Diabetes and Digestive and Kidney Diseases, 2010.

$\checkmark 4$ Collins AJ, Foley RN, Gilbertson DT, Chen SC: The state of chronic kidney disease, ESRD, and morbidity and mortality in the first year of dialysis. Clin J Am Soc Nephrol 2009;4(suppl 1):S5-S11.

5 Teo BW, Ma V, Xu H, Li J, Lee EJ: Profile of hospitalisation and death in the first year after diagnosis of end-stage renal disease in a multi-ethnic Asian population. Ann Acad Med Singapore 2010;39:79-87.

-6 Bradbury BD, Fissell RB, Albert JM, Anthony MS, Critchlow CW, Pisoni RL, Port FK, Gillespie BW: Predictors of early mortality among incident US hemodialysis patients in the Dialysis Outcomes and Practice Patterns Study (DOPPS). Clin J Am Soc Nephrol 2007; 2:89-99.

7 Levey AS, Greene T, Kusek JW, Beck GL, Group MS: A simplified equation to predict glomerular filtration rate from serum creatinine (abstract). J Am Soc Nephrol 2000;11: 155A.
-8 Owen WF Jr, Lew NL, Liu Y, Lowrie EG, Lazarus JM: The urea reduction ratio and serum albumin concentration as predictors of mortality in patients undergoing hemodialysis. $\mathrm{N}$ Engl J Med 1993;329:1001-1006.

$\checkmark 9$ Yamada S, Ishii H, Takahashi H, Aoyama T, Morita Y, Kasuga H, Kimura K, Ito Y, Takahashi R, Toriyama T, Yasuda Y, Hayashi M, Kamiya H, Yuzawa Y, Maruyama S, Matsuo S, Matsubara T, Murohara T: Prognostic value of reduced left ventricular ejection fraction at start of hemodialysis therapy on cardiovascular and all-cause mortality in end-stage renal disease patients. Clin J Am Soc Nephrol 2010;5:1793-1798.

10 Quinn RR, Laupacis A, Hux JE, Oliver MJ, Austin PC: Predicting the risk of 1-year mortality in incident dialysis patients: accounting for case-mix severity in studies using administrative data. Med Care 2011;49:257-266.

11 Kim do H, Kim M, Kim H, Kim YL, Kang SW, Yang CW, Kim NH, Kim YS, Lee JP: Early referral to a nephrologist improved patient survival: prospective cohort study for endstage renal disease in Korea. PloS One 2013; 8:e55323.

12 Cerasola G, Nardi E, Palermo A, Mule G, Cottone S: Epidemiology and pathophysiology of left ventricular abnormalities in chronic kidney disease: a review. J Nephrol 2011;24:1-10.

13 Foley RN, Parfrey PS, Harnett JD, Kent GM, Martin CJ, Murray DC, Barre PE: Clinical and echocardiographic disease in patients starting end-stage renal disease therapy. Kidney Int 1995; 47:186-192
14 Hung J, Harris PJ, Uren RF, Tiller DJ, Kelly DT: Uremic cardiomyopathy - effect of hemodialysis on left ventricular function in endstage renal failure. N Engl J Med 1980;302: 547-551.

15 Olesen JB, Lip GY, Kamper AL, Hommel K, Kober L, Lane DA, Lindhardsen J, Gislason GH, Torp-Pedersen C: Stroke and bleeding in atrial fibrillation with chronic kidney disease. N Engl J Med 2012;367:625-635.

16 Go AS, Fang MC, Udaltsova N, Chang Y, Pomernacki NK, Borowsky L, Singer DE: Impact of proteinuria and glomerular filtration rate on risk of thromboembolism in atrial fibrillation: the Anticoagulation and Risk Factors in Atrial Fibrillation (ATRIA) study. Circulation 2009;119:1363-1369.

17 Lash JP, Go AS, Appel LJ, He J, Ojo A, Rahman M, Townsend RR, Xie D, Cifelli D, Cohan J, Fink JC, Fischer MJ, Gadegbeku C, Hamm LL, Kusek JW, Landis JR, Narva A, Robinson N, Teal V, Feldman HI: Chronic renal insufficiency cohort (CRIC) study: baseline characteristics and associations with kidney function. Clin J Am Soc Nephrol 2009;4: 1302-1311.

18 Wagner M, Ansell D, Kent DM, Griffith JL, Naimark D, Wanner C, Tangri N: Predicting mortality in incident dialysis patients: an analysis of the United Kingdom Renal Registry. Am J Kidney Dis 2011;57:894-902.

19 Lukowsky LR, Kheifets L, Arah OA, Nissenson AR, Kalantar-Zadeh K: Patterns and predictors of early mortality in incident hemodialysis patients: new insights. Am J Nephrol 2012;35:548-558. 
20 Eustace JA, Astor B, Muntner PM, Ikizler TA, Coresh J: Prevalence of acidosis and inflammation and their association with low serum albumin in chronic kidney disease. Kidney Int 2004;65:1031-1040.

21 Soriano S, Gonzalez L, Martin-Malo A, Rodriguez M, Aljama P: C-reactive protein and low albumin are predictors of morbidity and cardiovascular events in chronic kidney disease (CKD) 3-5 patients. Clin Nephrol 2007; 67:352-357.

22 Kalantar-Zadeh K, Kuwae N, Regidor DL, Kovesdy CP, Kilpatrick RD, Shinaberger CS, McAllister CJ, Budoff MJ, Salusky IB, Kopple JD: Survival predictability of time-varying indicators of bone disease in maintenance hemodialysis patients. Kidney Int 2006;70:771780 .
23 Lomashvili KA, Garg P, Narisawa S, Millan JL, O'Neill WC: Upregulation of alkaline phosphatase and pyrophosphate hydrolysis: potential mechanism for uremic vascular calcification. Kidney Int 2008;73:1024-1030.

24 Neri L, Rocca Rey LA, Lentine KL, Hinyard LJ, Pinsky B, Xiao H, Dukes J, Schnitzler MA: Joint association of hyperuricemia and reduced GFR on cardiovascular morbidity: a historical cohort study based on laboratory and claims data from a national insurance provider. Am J Kidney Dis 2011;58:398-408.

25 Khosla UM, Zharikov S, Finch JL, Nakagawa T, Roncal C, Mu W, Krotova K, Block ER, Prabhakar S, Johnson RJ: Hyperuricemia induces endothelial dysfunction. Kidney Int 2005;67:1739-1742.
26 See LC, Kuo CF, Chuang FH, Li HY, Chen $\mathrm{YM}$, Chen HW, Yu KH: Serum uric acid is independently associated with metabolic syndrome in subjects with and without a low estimated glomerular filtration rate. J Rheumatol 2009;36:1691-1698.

27 Suliman ME, Johnson RJ, Garcia-Lopez E, Qureshi AR, Molinaei H, Carrero JJ, Heimburger O, Barany P, Axelsson J, Lindholm B, Stenvinkel P: J-shaped mortality relationship for uric acid in CKD. Am J Kidney Dis 2006; 48:761-771.

28 Kurella Tamura M, Covinsky KE, Chertow GM, Yaffe K, Landefeld CS, McCulloch CE: Functional status of elderly adults before and after initiation of dialysis. N Engl J Med 2009; 361:1539-1547. 